\title{
The prevalence and consequences of malnutrition risk in elderly Albanian intensive care unit patients
}

This article was published in the following Dove Press journal:

Clinical Interventions in Aging

16 February 2015

Number of times this article has been viewed

\author{
Vjollca Shpata' \\ Ilir Ohri \\ Tatjana Nurka' \\ Xhensila Prendushi' \\ 'Faculty of Medical Technical Sciences, \\ "University Hospital Center of \\ Tirana "Mother Theresa", Faculty of \\ Medicine, University of Medicine in \\ Tirana, Tirana, Albania
}

Purpose: Many investigators have reported rising numbers of elderly patients admitted to the intensive care units (ICUs). The aim of the study was to estimate the prevalence of malnutrition risk in the ICU by comparing the prevalence of malnutrition between older adults (aged 65 years and above) and adults (aged 18-64 years), and to examine the negative consequences associated with risk of malnutrition in older adults.

Materials and methods: A prospective cohort study in the ICU of the University Hospital Center of Tirana, Albania, was conducted. Logistic regression analysis was used to analyze the effect of malnutrition risk on the length of ICU stay, the duration of being on the ventilator, the total complications, the infectious complications, and the mortality.

Results: In this study, 963 patients participated, of whom 459 patients $(47.7 \%)$ were aged $\geq 65$ years. The prevalence of malnutrition risk at the time of ICU admission of the patients aged $\geq 65$ years old was $71.24 \%$. Logistic regression adjusted for confounders showed that malnutrition risk was an independent risk factor of poor clinical outcome for elderly ICU patients, for 1) infections (odds ratio $[\mathrm{OR}]=4.37$; 95\% confidence interval $[\mathrm{CI}]: 2.61-7.31$ ); 2) complications ( $\mathrm{OR}=6.73$; 95\% CI: 4.26-10.62); 3) mortality ( $\mathrm{OR}=2.68$; 95\% CI: 1.72-4.18); and 4) ICU length of stay $>14$ days (OR $=5.18,95 \% \mathrm{CI}: 2.43-11.06)$.

Conclusion: Malnutrition risk is highly prevalent among elderly ICU patients, especially among severely ill patients with malignancy admitted to the emergency ward. ICU elderly patients at malnutrition risk will have higher complication and infection rates, longer duration of ICU stay, and increased mortality. Efforts should be made to implement a variety of nutritional care strategies, to change the nutritional practices not only at ward level, but nationally, according to the best clinical practice and recent guidelines.

Keywords: elderly ICU patients, ICU mortality, morbidity, malnutrition risk

\section{Introduction}

The geriatric population worldwide is growing immensely every day. ${ }^{1}$ The population in Albania $\geq 65$ years of age will increase 140\% during the 1994-2020 time period, according to the projected percentage increase in this population. ${ }^{1}$

This increase in the geriatric population will accordingly raise the number of critically ill elderly patients who are more prone to admission at the intensive care unit (ICU). Investigators have reported a rising number of elderly patients admitted to the ICUs in various countries. ${ }^{2-4}$

Malnutrition in the aging and chronically ill population is an important issue that has been seen in hospitals, ${ }^{5}$ because there are many changes associated with the process of aging that can promote malnutrition. ${ }^{6}$ Other risk factors for malnutrition in the elderly are chronic diseases, organic disorders, drug interactions, physical disability; ${ }^{7}$ lifestyle and social factors ${ }^{8}$ and the psychological factors such as confusion, dementia, depression, bereavement, and anxiety. ${ }^{7}$ 
Elderly patients admitted to the ICU are an exceptionally vulnerable patient population. ${ }^{9}$ Often these patients have several conditions that impede oral intake and impair nutritional status. When coupled with an acute disease process, it is likely that elderly patients in ICU are at exceptional risk for nutritional deterioration. ${ }^{9}$ The geriatric population is associated with increased mortality rates in ICU patients, ${ }^{10}$ and data about nutritional status should be collected to predict mortality in elderly ICU patients. ${ }^{11}$

Data defining how malnutrition or malnutrition risk affects the outcome in elderly patients (aged $\geq 65$ years), who represent approximately half the ICU admissions ${ }^{12}$ in Albania, is not sufficient, and the ICU mortality rate associated with malnutrition risk has not been defined in Albanian ICU patients $\geq 65$ years of age. Also, in international medical studies, there are gaps in data describing the prevalence of malnutrition or malnutrition risk in elderly ICU patients. ${ }^{9}$

The aim of the study was therefore threefold: 1) to estimate the prevalence of malnutrition risk in the ICU, comparing the prevalence between older adults (aged 65 years and above) and adults (aged 18-64 years); 2) to examine the negative consequences associated with risk of malnutrition in older adults; and 3) to determine the difference in morbidity and mortality in age-related groups of ICU patients and to identify the risk factors for mortality of elderly patients in the ICU.

\section{Materials and methods}

A prospective cohort study was conducted in the 15-bed ICU at the University Hospital Center of Tirana "Mother Theresa" in Tirana, Albania, between January 2011 and December 2013. Throughout this period, consecutive patients aged $>18$ years admitted to the medical and surgical ICUs were enrolled in the study. We excluded from the study patients that stayed $<72$ hours and patients that stayed in the ICUs for temporary monitoring. The age cutoff point defining an elderly patient was 65 years of age.

This study was approved by the Ethics Committee of the University of Medicine, Tirana, Albania. It has been performed in accordance with the ethical standards displayed in the 1964 Declaration of Helsinki and its later amendments. Data were made anonymous for analysis.

\section{Patient data}

We recorded demographic variables (age and sex), admission diagnosis (medical or surgical), and type of hospital admission (emergency or elective). We recorded preexisting conditions as comorbidities: cardiac diseases, neurological diseases, pulmonary diseases, gastrointestinal diseases, endocrinological diseases, and postoperative conditions (postoperative chronic cardiovascular disease, postoperative hemorrhagic shock, postoperative gastrointestinal bleeding, postoperative gastrointestinal neoplasm, postoperative respiratory insufficiency, and postoperative gastrointestinal obstruction/perforation). To determine the influence of severity of illness on the ICU mortality rates, we evaluated the severity of illness using the Acute Physiological and Chronic Health Evaluation (APACHE II) ${ }^{13}$ within the first 24 hours of ICU admission.

\section{Assessment of the malnutrition risk}

The nutritional status of the study participants was assessed within the first 24 hours following ICU admission using the Nutritional Risk Screening 2002 (NRS 2002). ${ }^{14}$ NRS 2002, the nutritional screening tool proposed by the European Society for Clinical Nutrition and Metabolism (ESPEN) guidelines for the nutritional screening of adult hospitalized patients, ${ }^{15}$ combines two scores, the "nutritional score" of $0-3$ and the "severity of disease score" of $0-3$, plus one point if the patient is above 70 years of age.

A variety of malnutrition screening tools has been developed over the last decade, ${ }^{16}$ but in our study to assess the malnutrition risk, we used the NRS 2002, endorsed by ESPEN, ${ }^{14,15}$ because it is a widely used instrument in Europe, it requires only simple training to use it, ${ }^{16}$ and it is considered an easy-to-perform and quick screening tool, which does not require additional calculations (eg, the calculations of BMI). Those calculations may be inaccurate in ICU settings because of resuscitative fluid administration ${ }^{17}$ or edema formation. ${ }^{18}$

The nutrition screening tools determine the risk of malnutrition, ${ }^{19}$ and according to the NRS 2002, we considered two categories of patients: 1) patients not at risk of malnutrition (NRS 2002 score $<3$ ); and 2) patients at risk of malnutrition (NRS 2002 score $\geq 3$ ).

\section{Complications, mortality, duration of being on a ventilator, and ICU stay}

Duration of ICU stay and length of ventilator use, total complications, ICU-acquired infections, and ICU mortality were recorded. Complications were defined as the appearance of a morbid condition in addition to the preexisting condition that led to ICU admission, without requiring a specific relationship between the two variables. ICU-acquired infections (infections that become evident 48 hours or more after admission in the ICU) included systemic inflammatory response syndrome, ${ }^{20}$ pneumonia, urinary tract infection, central 
venous catheter sepsis, sepsis, ${ }^{21}$ and wound infection. ${ }^{22}$ Other complications included postoperative complications (open abdominal wound, postoperative bleeding, and anastomotic leak) and organ failures (Sequential Organ Failure Assessment [SOFA] score $>2$ for any of the six organs/systems evaluated, and MOF (multiple organ failure) for more than one failing organ). ${ }^{23}$ The duration of time in the ICU was defined as the time from admission of patients until they were ready for discharge, or until ICU death. All patients were followed up clinically until leaving the ICU or death, and their outcomes were recorded.

\section{Statistical analysis}

Continuous variables were presented as the mean \pm SD (standard deviation). Categorical variables were expressed as actual numbers (n) and percentages (\%). Variables of malnutrition risk and ICU mortality were assessed in the groups of patients stratified according to age range (18-64 years, 65-74 years, $75-84$ years, and aged $\geq 85$ years). A cohort of patients aged $\geq 65$ years was selected for outcome analysis and distributed into subgroups according to age. Chi-square analysis was applied to compare frequencies between subgroups, and Student's $t$-tests, or non-parametric tests when necessary, were employed for quantitative variable analysis. NRS 2002 score was handled as a binary variable; patients with an NRS 2002 score $\geq 3$ were considered at malnutrition risk and patients with an NRS 2002 score $<3$ were considered not at malnutrition risk.

Multivariate analysis was conducted using a logistic regression model in which "at risk of malnutrition" was used as the dependent variable. Logistic regression analysis was used to analyze the effect of malnutrition risk on the length of ICU stay, the duration of being on the ventilator, the total complications, the infectious complications, and the ICU mortality. The correlation between malnutrition risk and clinical outcome was assessed and adjusted for confounders (age of patients, admitting diagnoses, the severity of illness, the number of comorbidities at admission [the preexisting conditions], sex, the type of hospital admission [elective or emergency], and impaired levels of consciousness).

Multivariate analysis and identification of the independent factors associated with ICU mortality was achieved through the adjustment of a logistic regression model by the statistical software Statistics Package for Social Scientists version 15.0. Only the variables associated with ICU mortality that yielded $P$-values lower than 0.10 in the initial analysis were used in the stepwise logistic regression analysis. Odds ratios (ORs) and $95 \%$ confidence intervals ( $95 \% \mathrm{CIs})$ were used to estimate the association between death and the independent determinants of ICU mortality. Statistical significance was considered to be at the level of $P \leq 0.05$. All tests were two-tailed.

\section{Results}

In this study, 963 patients participated, of whom 459 patients (47.7\%) were aged $\geq 65$ years and 242 patients $(25.1 \%$ of the study patients) were aged $\geq 75$ years. Table 1 presents baseline demographic and clinical characteristics of the patient population. In the present study geriatric patients are more likely to be admitted in the ICU after major abdominal surgery. The prevalence of the preexisting conditions does not change between older age and non-older age patients. A significant difference was observed in age-related morbidity. Compared with younger patients, elderly patients were more likely to be more severely ill on the first day in the ICU (APACHE II scores: $15.49 \pm 4.91$ vs $19.02 \pm 5.56$, respectively: younger vs elderly patients, $P<0.0001$ ).

Elderly ICU patients had higher severity of illness, higher rate of ICU-acquired infections, higher rate of organ failure during ICU stay, and had a higher risk for mortality compared to the younger patients (Table 1). Patients aged $\geq 65$ years remained longer on mechanical ventilation and stayed longer in the ICU.

Table I Comparison of the characteristics of ICU patients divided into groups according to the age-group (older age and nonolder age)

\begin{tabular}{|c|c|c|}
\hline Characteristics & $<65$ years old & $\geq 65$ years old \\
\hline Number of patients (\%) & $504(52.3 \%)$ & $459(47.7 \%)$ \\
\hline Age* & $48.45 \pm 12.07$ & $74.4 I \pm 5.93$ \\
\hline \multicolumn{3}{|l|}{ Sex } \\
\hline Female & 226 (44.85\%) & 189 (4I.| $8 \%)$ \\
\hline Male & 278 (55.15\%) & 270 (58.82\%) \\
\hline \multicolumn{3}{|l|}{ Type of patients } \\
\hline Medical & $173(34.33 \%)$ & $96(20.92 \%)$ \\
\hline Surgical* & 331 (65.67\%) & $363(79.08 \%)$ \\
\hline Prevalence of preexisting conditions & 116 (23.01\%) & 127 (27.66\%) \\
\hline APACHE II score* & $|5.49 \pm 4.9|$ & $19.02 \pm 5.56$ \\
\hline APACHE II score $\geq 15^{*}$ & $252(50 \%)$ & $358(77.99 \%)$ \\
\hline Emergency admission & I 54 (30.55\%) & 149 (32.46\%) \\
\hline Malnutrition risk* & $276(54.7 \%)$ & 327 (71.24\%) \\
\hline ICU LOS (days)* & $7.74 \pm 6.09$ & $10.56 \pm 9.65$ \\
\hline MV LOS (days)* & $1.66 \pm 3.83$ & $2.53 \pm 4.59$ \\
\hline ICU-acquired infection* & I5I (29.9\%) & $169(36.8 \%)$ \\
\hline Organ failure during stay in the ICU* & I0I (20.04\%) & 164 (35.73\%) \\
\hline Complications* & $255(50.59 \%)$ & $263(57.29 \%)$ \\
\hline Died in the ICU* & 118 (23.4\%) & $196(42.7 \%)$ \\
\hline
\end{tabular}

Notes: $* P$-value $<0.05$. Data are expressed as mean $\pm S D$, or number $(\%)$ of patients.

Abbreviations: ICU, intensive care unit; ICU LOS, intensive care unit length of stay; MV LOS, mechanical ventilation length of stay; APACHE II, Acute Physiological Chronic Health Evaluation II. 
According to the NRS 2002, 62.6\% of the study population was at risk of malnutrition. The prevalence of malnutrition risk in the sample of older patients was $71.24 \%$, and $54.7 \%$ in the patients younger than 65 years old.

The risk of malnutrition increased progressively after the age of 65 years, compared to the risk of malnutrition in patients younger than 65 years old (Table 2).

Multivariate logistic regression analysis identified the following factors as independent risk factors for malnutrition risk in elderly patients: 1 ) age of patients ( $\mathrm{OR}=1.07,95 \% \mathrm{CI}$ : $1.02-1.11 ; P=0.001) ; 2$ ) APACHE II score $\geq 15$ (OR $=3.06$, 95\% CI: $1.85-5.04 ; P<0.0001)$; 3) presence of malignancy ( $\mathrm{OR}=3.06,95 \%$ CI: $1.67-5.58 ; P=0.0003)$; and 4$)$ emergency hospital admission ( $\mathrm{OR}=1.86,95 \% \mathrm{CI}: 1.12-3.10 ; P=0.01)$. Other factors included in this multivariate logistic regression analysis were admitting diagnoses, the number of comorbidities at admission (the preexisting conditions), and sex.

Logistic regression showed that malnutrition risk was an independent risk factor for variables of ICU clinical outcome for elderly patients; malnutrition was also a risk factor for 1) ICU-acquired infections ( $\mathrm{OR}=4.37,95 \%$ CI: $2.61-7.31 ; P<0.0001) ; 2)$ organ failures $(\mathrm{OR}=4.10$, 95\% CI: 2.45-6.87; $P<0.0001)$; 3) complications (OR $=6.73,95 \%$ CI: 4.26-10.62; $P<0.0001)$; 4) mortality (OR $=2.68,95 \%$ CI: $1.72-4.18 ; P<0.0001)$; and 5$)$ ICU length of stay longer than 14 days (OR $=5.18,95 \%$ CI: $2.43-11.06$; $P<0.0001)$. Logistic regression was adjusted for confounders such as age of patients, admitting diagnoses, the severity of illness, the number of comorbidities at admission (the preexisting conditions), sex, the type of hospital admission (elective or emergency), and impaired levels of consciousness.

Table 3 shows the result of multivariate logistic regression analysis of the factors identified as independent predictors of elderly ICU mortality. Other factors included in this multivariate logistic regression analysis were admitting diagnoses, the number of comorbidities at admission, sex, the type of hospital admission (elective or emergency), and impaired levels of consciousness. We did not find any correlation between the numbers of comorbidities at admission and

Table 2 Logistic regression for the risk of malnutrition according to the age-group of patients, using the age-group aged 18-64 years as a reference group

\begin{tabular}{llll}
\hline Age of patients & OR & $\mathbf{9 5 \%} \mathbf{C l}$ & $P$-value \\
\hline I8-64 years & Ref & - & - \\
$65-74$ years & 1.43 & $1.04-1.95$ & 0.02 \\
$75-84$ years & 3.07 & $2.08-4.54$ & $<0.000 \mathrm{I}$ \\
$\geq 85$ years & 9.08 & $2.11-39.05$ & 0.003 \\
\hline
\end{tabular}

Abbreviations: Ref, reference; OR, odds ratio; $\mathrm{Cl}$, confidence interval.
Table 3 Results of multivariate analysis for significant risk factors for ICU mortality in the group of patients aged $\geq 65$ years old

\begin{tabular}{llll}
\hline Risk factors & OR & $\mathbf{9 5 \% ~ C I ~}$ & P-value \\
\hline Malnutrition risk & 2.68 & $1.72-4.18$ & $<0.000$ I \\
Age of patients & 1.12 & $1.08-1.16$ & $<0.000$ I \\
APACHE II score $\geq I 5$ & 2.77 & $1.69-4.57$ & $<0.000$ I \\
ICU LOS $>$ I4 days & 1.80 & $1.13-2.87$ & 0.01 \\
Presence of ICU-acquired infection & 1.97 & $1.34-2.90$ & 0.0005 \\
Presence of organ failure during ICU stay & 4.95 & $3.28-7.46$ & $<0.000$ I \\
Complications & 3.35 & $2.24-4.99$ & $<0.000$ I \\
Days on mechanical ventilation & 1.05 & $1.0 I-I .10$ & 0.006 \\
\hline
\end{tabular}

Abbreviations: $\mathrm{OR}$, odds ratio; $\mathrm{Cl}$, confidence interval; ICU, intensive care unit; APACHE II, Acute Physiological Chronic Health Evaluation II; ICU LOS, intensive care unit length of stay.

the elderly ICU mortality. ICU mortality rate was $32.6 \%$. Out of 459 patients aged $\geq 65$ years, 196 patients $(42.7 \%)$ died during ICU stay, and 162 patients $(82.65 \%$ of the patients aged $\geq 65$ years who died) were at malnutrition risk. The group of patients aged 75-84 years had a more than doubled ICU mortality compared with patients aged $<65$ years (60.31\% vs $23.41 \%$, respectively; $P<0.0001)$. Also, patients older than 85 years had a more than tripled ICU mortality compared with patients aged $<65$ years $(79.16 \%$ vs $23.41 \%$, respectively; $P<0.0001)$.

\section{Discussion}

As we are encountering more elderly ICU patients together with an increasing geriatric population, we have shown that an ICU patient group particularly predisposed to the risk of malnutrition is the elderly population. The prevalence of malnutrition risk rises with age, and it is associated with increased risk for ICU-acquired infections, complications, longer ICU stay, and ICU mortality. Various studies ${ }^{24,25}$ have shown that different age-groups of patients are at risk of malnutrition. The use of a diversity of screening tools can be an explanation for the wide range of findings.

The prevalence of malnutrition in the hospitalized geriatric population ranges from $6.6 \%$ to $85 \%$, depending on the method used for diagnosis. ${ }^{26}$

The prevalence of the malnutrition risk is higher in our study, together with some other recent studies, ${ }^{27,28}$ because it has been reported the risk of malnutrition and not the presence of malnutrition per se. The results in our study are comparable with the results of a large study (EuroOOPS), ${ }^{29}$ which showed that $48 \%-57 \%$ of the geriatric patients in Western Europe are "at nutritional risk", while these percentages were increased to $87 \%-100 \%$ of the intensive care patients (and 100\% in Eastern Europe, of which Albania is a part). Also, the EuroOOPS study ${ }^{29}$ showed that nutritional risk is associated with a poor 
clinical outcome. Giner et al also showed that malnourished patients in an ICU have a poorer prognosis and survival. ${ }^{30} \mathrm{In}$ our study, as in others, malnutrition risk was associated with increased odds of mortality and poor clinical outcome. ${ }^{31,32}$

Screening for nutritional risk is an essential first step in the structured process of nutrition care ${ }^{15}$ for identifying patients who will likely benefit from nutritional therapy. Identification of at malnutrition risk patients should be linked to recommendations for appropriate action, or referral for dietetic intervention. ${ }^{15,33}$

Although the role of the ICU dietitian in improving nutritional support is established by studies, ${ }^{34-36}$ there are still no qualified dietitians present in Albanian ICUs to address the problem. The overwhelmed ICU personnel usually underprescribe nutritional therapy. Therefore, the consequences of malnutrition in the worsening of the ICU outcome for elderly patients are worse.

In contradiction to guidelines and the best evidence, ${ }^{37,38}$ in our ICU, the enteral route is not the main route of administering nutritional support, and parenteral nutrition is frequently used. The reasons for this nutritional routine are 1) the limited pharmacy stock (ICU personnel are constricted to use what is available); 2) the lack of enteral access in the majority of the patients; and 3) the absence of national standardized guidelines/protocols for the provision of nutritional support.

\section{Limitations of the study}

Although this study represents the first attempt to evaluate prevalence of malnutrition risk and its effects on the outcome of elderly ICU patients, one possible limitation is that the study was conducted in a single center. As a tertiary center, this ICU receives referrals of complicated medical and surgical cases with high levels of severity of illness.

\section{Conclusion}

Risk of malnutrition is high among elderly ICU patients. Our study showed that elderly patients are predisposed to malnutrition, especially severely ill patients with malignancy admitted to the emergency ward. Elderly ICU patients at risk of malnutrition will have more complications and higher infection rates, longer duration of ICU stay, and increased mortality, leading to increased costs for the health care system and society overall.

Efforts should be made to implement a variety of nutritional care strategies, to change the nutritional practices not only at ward level, but nationally, according to the best clinical practice and recent guidelines. Also, dietitians should be available in the ICU setting, in order to improve nutritional practices and consequently the clinical outcomes of ICU patients.

\section{Disclosure}

The authors report no conflicts of interest in this work.

\section{References}

1. Butler RN. Population aging and health. BMJ. 1997;315:1082-1084.

2. Fowler RA, Adhikari NK, Bhagwanjee S. Clinical review: critical care in the global context - disparities in burden of illness, access, and economics. Crit Care. 2008;12:225.

3. Nguyen YL, Angus DC, Boumendil A, Guidet B. The challenge of admitting the very elderly to intensive care. Ann Intensive Care. 2011;1:29.

4. Angus DC, Kelley MA, Schmitz RJ, White A, Popovich J Jr; Committee on Manpower for Pulmonary and Critical Care Societies (COMPACCS). Caring for the critically ill patient. Current and projected workforce requirements for care of the critically ill and patients with pulmonary disease: can we meet the requirements of an aging population? JAMA 2000;284:2762-2770.

5. Corish CA, Kennedy NP. Protein-energy undernutrition in hospital in-patients. Br J Nutr. 2000;83:575-591.

6. Landi F, Zuccalà G, Gambassi G, et al. Body mass index and mortality among older people living in the community. J Am Geriatr Soc. 1999 47:1072-1076.

7. Hickson M. Malnutrition and ageing. Postgrad Med J. 2006;82:2-8.

8. Payette H, Gray-Donald K, Cyr R, et al. Predictors of dietary intake in a functionally dependent elderly population in the community. $\mathrm{Am} \mathrm{J}$ Public Health. 1995;85:677-683.

9. Sheean PM, Peterson SJ, Chen Y, Liu D, Lateef O, Braunschweig CA. Utilizing multiple methods to classify malnutrition among elderly patients admitted to the medical and surgical intensive care units (ICU) Clin Nutr. 2013;32(5):752-757.

10. Wood KA, Ely EW. What does it mean to be critically ill and elderly? Curr Opin Crit Care. 2003;9:316-320.

11. Boumendil A, Somme D, Garrouste-Orgeas M, Guidet B. Should elderly patients be admitted to the intensive care unit? Intensive Care Med. 2007;33:1252-1262.

12. Fuchs L, Chronaki CE, Park Sh, et al. ICU admission characteristics and mortality rates among elderly and very elderly patients. Intensive Care Med. 2012;38:1654-1661.

13. Knaus WA, DraperEA, WagnerDP, Zimmerman JE. APACHE II: a severity of disease classification system. Crit Care Med. 1985;13:818-829.

14. Kondrup J, Rasmussen HH, Hamberg O, Stanga Z; Ad Hoc ESPEN Working Group. Nutritional risk screening (NRS 2002): a new method based on an analysis of controlled clinical trials. Clin Nutr. 2003;22:321-336.

15. Kondrup J, Allison SP, Elia M, Vellas B, Plauth M; Educational and Clinical Practice Committee, European Society of Parenteral and Enteral Nutrition (ESPEN). ESPEN guidelines for nutrition screening 2002. Clin Nutr. 2003;22:415-421.

16. van Bokhorst-de van der Schueren MAE, Soeters PB, Reijven PLM, Allison SP, Kondrup J. Diagnosis of malnutrition - screening and assessment. In: Sobotka L, editor. Basics in Clinical Nutrition. 4th ed Prague: Galen; 2011:21-32.

17. Griffiths RD, Bongers T. Nutrition support for patients in the intensive care unit. Postgrad Med J. 2005;81:629-636.

18. Webster NR, Galley HF. Nutrition in the critically ill patient. JR Coll Surg Edinb. 2000;45:373-379.

19. Marshall S, Bauer J, Isenring E. The consequences of malnutrition following discharge from rehabilitation to the community: a systematic review of current evidence in older adults. J Hum Nutr Diet. 2014;27: $133-141$. 
20. Bone RC, Balk RA, Cerra FB, et al. Definitions for sepsis and organ failure and guidelines for the use of innovative therapies in sepsis. The ACCP/SCCM Consensus Conference Committee. American College of Chest Physicians/ Society of Critical Care Medicine. Chest. 1992;101(6):1644-1655.

21. Levy MM, Fink MP, Marshall JC, et al; SCCM/ESICM/ACCP/ATS/ SIS. $2001 \mathrm{SCCM} / \mathrm{ESICM} / \mathrm{ACCP} / \mathrm{ATS} / \mathrm{SIS}$ International Sepsis Definitions Conference. Crit Care Med. 2003;31:1250-1256.

22. Garner JS, Jarvis WR, Emori TG, Horan TC, Hughes JM. CDC definitions for nosocomial infections, 1988. Am J Infect Control. 1988; 16:128-140.

23. Vincent JL, de Mendonça A, Cantraine F, et al. Use of the SOFA score to assess the incidence of organ dysfunction/failure in intensive care units: results of a multicenter, prospective study. Working group on "sepsis-related problems" of the European Society of Intensive Care Medicine. Crit Care Med. 1998;26:1793-1800.

24. Pirlich M, Schutz T, Norman K., Gastell S, Lubke HF, Bischoff, Bolder U. The German hospital malnutrition study. Clin Nutr. 2006;25: 563-572.

25. British Association of Parenteral and Enteral Nutrition. Nutrition Screening Survey in the UK in 2008; British Association of Parenteral and Enteral Nutrition: Redditch, UK, 2009.

26. Joosten E, Vanderelst B, Pelemans W. The effect of different diagnostic criteria on the prevalence of malnutrition in a hospitalized geriatric population. Aging (Milano). 1999;11:390-394.

27. de Groot CP, van Staveren WA; Survey in Europe on Nutrition and the Elderly, a Concerted Action. Undernutrition in the European SENECA studies. Clin Geriatr Med. 2002;18:699-708.

28. Keller HH. Malnutrition in institutionalized elderly: how and why? J Am Ger Soc. 1993;41:1212-1218.

29. Sorensen J, Kondrup J, Prokopowicz J, et al; EuroOOPS study group. EuroOOPS: an international, multicentre study to implement nutritional risk screening and evaluate clinical outcome. Clin Nutr. 2008;27:340-349.
30. Giner M, Laviano A, Meguid MM, Gleason JR. In 1995 a correlation between malnutrition and poor outcome in critically ill patients still exists. Nutrition. 1996;12:23-29.

31. Bo M, Massaia M, Raspo S, et al. Predictive factors of in-hospital mortality in older patients admitted to a medical intensive care unit. $J$ Am Geriatr Soc. 2003;51:529-533.

32. Covinsky KE, Martin GE, Beyth RJ, Justice AC, Sehgal AR, Landefeld CS. The relationship between clinical assessments of nutritional status and adverse outcomes in older hospitalized medical patients. J Am Geriatr Soc. 1999;47:532-538.

33. O'Flynn J, Peake H, Hickson M, Foster D, Frost G. The prevalence of malnutrition in hospitals can be reduced: Results from three consecutive cross-sectional studies. Clinical Nutrition. 2005;24:1078-1088.

34. Taylor B, Renfro A, Mehringer L. The role of the dietitian in the intensive care unit. Curr Opin Clin Nutr Metab Care. 2005;8:211-216.

35. Braga JM, Hunt A, Pope J, Molaison E. Implementation of dietitian recommendations for enteral nutrition results in improved outcomes. J Am Diet Assoc. 2006;106:281-284.

36. Soguel L, Revelly JP, Schaller MD, Longchamp C, Berger MM. Energy deficit and length of hospital stay can be reduced by a two-step quality improvement of nutrition therapy: the intensive care unit dietitian can make the difference. Crit Care Med. 2012;40(2):412-419.

37. McClave SA, Martindale RG, Vanek VW, et al; A.S.P.E.N. Board of Directors; American College of Critical Care Medicine; Society of Critical Care Medicine. Guidelines for the provision and assessment of nutrition support therapy in the adult critically ill patient: Society of Critical Care Medicine (SCCM) and American Society for Parenteral and Enteral Nutrition (A.S.P.E.N.). JPEN J Parenter Enteral Nutr. 2009;33(3):277-316.

38. Kreymann KG, Berger MM, Deutz NE, et al; DGEM (German Society for Nutritional Medicine); ESPEN (European Society for Parenteral and Enteral Nutrition). ESPEN guidelines on enteral nutrition: intensive care. Clin Nutr. 2006;25:210-223.
Clinical Interventions in Aging

\section{Publish your work in this journal}

Clinical Interventions in Aging is an international, peer-reviewed journal focusing on evidence-based reports on the value or lack thereof of treatments intended to prevent or delay the onset of maladaptive correlates of aging in human beings. This journal is indexed on PubMed Central, MedLine,

\section{Dovepress}

CAS, Scopus and the Elsevier Bibliographic databases. The manuscript management system is completely online and includes a very quick and fair peer-review system, which is all easy to use. Visit http://www.dovepress. com/testimonials.php to read real quotes from published authors. 